ANL-5183

Physics and Mathematics

ARGONNE NATIONAL LABORATORY

P. O. Box 299

Lemont, Illinois

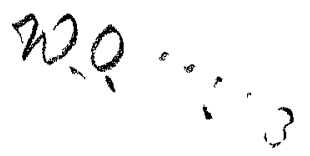

\title{
DETERMINATION OF URANIUM BURNUP BY NOMOGRAPHS \\ by
}

F. A. Taraba

METALLURGY DIVISION

Program 6.1.8

Décember 1953

Operated by The University of Chicago under

Contract W-38-109-eng-38 


\section{DISCLAIMER}

This report was prepared as an account of work sponsored by an agency of the United States Government. Neither the United States Government nor any agency Thereof, nor any of their employees, makes any warranty, express or implied, or assumes any legal liability or responsibility for the accuracy, completeness, or usefulness of any information, apparatus, product, or process disclosed, or represents that its use would not infringe privately owned rights. Reference herein to any specific commercial product, process, or service by trade name, trademark, manufacturer, or otherwise does not necessarily constitute or imply its endorsement, recommendation, or favoring by the United States Government or any agency thereof. The views and opinions of authors expressed herein do not necessarily state or reflect those of the United States Government or any agency thereof. 


\section{DISCLAIMER}

Portions of this document may be illegible in electronic image products. Images are produced from the best available original document. 
DETERMINATION OF URANIUM BURNUP BỸ NOMOGRAPHS

by

F. R. Taraba

\section{INTRODUCTION}

A series of nomographs has been constructed to solve the burnup equation

$$
\mathbf{B}=\mathbf{E}\left(1-e^{-\sigma \phi t}\right)
$$

where

$$
\begin{aligned}
\mathbf{B}= & \text { Per cent burnup of uranium atoms. } \\
\mathbf{E}= & \text { Per cent } \mathrm{U}^{235} \text { enrichment. } \\
\sigma= & \text { Thermal neutron cross section for fission of } \mathrm{U}^{235} \text {, in } \mathrm{cm}^{2} . \\
& \text { (Assumed a constant in constructing the nomographs.) } \\
\phi= & \text { Thermal neutron flux, neutrons per } \mathrm{cm}^{2} \text { per second. } \\
t= & \text { Time of irradiation, seconds. }
\end{aligned}
$$

Although the burnup equation (1) is explicitly solved for the variable $\underline{B}$, it is none the less true that, if any three of the variables $\phi, t, B$, and $E$ are known, the value for the remaining variable may be found most easily by means of the nomographs.

The use of the nomographs is described, and example problems are given to illustrate the procedure for solving the burnup equation. Included is an explanation of the important features of construction of the nomographs and a brief evaluation of their limitations.

\section{FEATURES OF CONSTRUCTION}

All scales of the nomographs are logarithmic.

It has been found convenient to introduce two auxiliary scales, $\underline{D}$ and $\underline{D}^{\prime}$, in the graphical solution of equation (1).

$\underline{D}$ and $\underline{D}^{\prime}$ are introduced as auxiliary variables to avoid the need for a curved scale. They are numerically equivalent and correspond to the same variable, namely, that associated with the depletion of the $\mathrm{U}^{235}$. However, the scales identified with them are not geometrically equivalent. 
In the construction of the nomographic solution of equation (1) the points associated with each of the variables, $\phi, t, B, E, D$, and $D^{\prime}$, have been scaled so that the combinations $(\phi, t, D)$ and $\left(E, B, D^{\prime}\right)$ lie along straight lines. This important property of the nomographs makes it possible to solve the burnup equation for any of the variables $\phi, t, B$, and $E$ if information pertaining to the remaining three variables is available.

\section{USE OF THE NOMOGRAPHS}

A series of three nomographs, in which the thermal neutron flux variable, $\phi$, ranges between $1.0 \times 10^{12}$ and $1.0 \times 10^{15} \mathrm{nv}$, is provided. The time variable, $t$, ranges between 5 and 200 days on two of the nomographs and between 10 and 400 days on the other.

To solve for either of the variables $\phi$ or $t$ obtain $D^{\prime}$ as the intersection of the $\underline{D}^{\prime}-s c a l e$ and the straight line determined by the points $E$ and $B$; locate the value of $\underline{D}^{\prime}$ on the $D-s c a l e$; locate the value of the desired variable, $\phi$ (or $t$ ), at the intersection of the $\phi$-scale (or t-scale) and the straight line determined by the points $\underline{D}$ and $\underline{t}(\operatorname{or} \Phi)$.

To solve for either $\underline{E}$ or $\underline{B}$ obtain $\underline{D}$ as the intersection of the D-scale and the straight line determined by the points $\Phi$ and $t ;$ locate the value of $\underline{D}$ on the $D^{\prime}$-scale; locate value of the desired variable, $\underline{B}$ (or $E$ ), at the intersection of the B-scale (or E-scale) and the straight line determined by the points $\underline{D}$ 'and $\underline{E}$ (or $\underline{B})$.

The procedure for the nomographic solution of the burnup equation may be expressed symbolically in the form of a table.

\begin{tabular}{|c|c|c|c|}
\hline $\begin{array}{c}\text { Known } \\
\text { Variables }\end{array}$ & $\begin{array}{l}\text { Unknown } \\
\text { Variables }\end{array}$ & First Step & Second Step \\
\hline$\phi, t, E$ & B & $\phi x t=D$ & $D^{\prime} \times E=B$ \\
\hline$\phi, t, B$ & $\mathbf{E}$ & $\phi x t=D$ & $D^{\prime} \times B=E$ \\
\hline$\phi, \mathbf{E}, \mathbf{B}$ & $\mathrm{t}$ & $\mathbf{E} \times \mathbf{B}=\mathbf{D}^{\prime}$ & $D \times \phi=t$ \\
\hline$t, E, B$ & $\phi$ & $\mathbf{E} \times \mathbf{B}=\mathbf{D}^{-}$ & $D \times t=\phi$ \\
\hline
\end{tabular}

The use of the auxiliary scales in conjunction with the other variables is illustrated by means of the following example problems:

Example 1.

Given: $\phi=3.5 \times 10^{13} \mathrm{nv}, \mathrm{t}=100$ days, and $\mathrm{E}=10 \%$ (by weight)

To find: Total atom burnup, $\mathbf{B} \%$

(a) Refer to nomograph of proper range 
(b) Find $\underline{D}$ as the intersection of the $D$-scale and the straight line determined by the points $\phi=3.5 \times 10^{13}$ and $t=100$. $\mathrm{D}=13.5 \%$

(c) Locate the value of $\underline{D}$ on the $D^{\prime}-$ scale

(d) Find $B$ as the intersection of the B-scale and the straight line determined by the points $D^{\prime}=13.5 \%$ and $E=10 \%$. $\mathrm{B}=1.4 \%$

Example 2.

Given: $\quad B=2.0 \%, E=5 \%, t=60$ days

To find: Thermal neutron flux,

(a) Refer to nomograph of proper range

(b) Find $D^{\prime}$ as the intersection of the $D^{\prime}-$ scale and the straight line determined by the points $B=2.0 \%$ and $E=5 \% . D^{\prime}=40 \%$.

(c) Locate the value of $\underline{D}^{\prime}$ on the D-scale

(d) Find $\phi$ as the intersection of the $\phi$-scale and the straight line determined by the points $D=40 \%$ and $t=60$ days. $\phi=2 \times 10^{14} \mathrm{nv}$.

\section{DISCUSSION}

The ranges of the scales of the nomographs are considered great enough for the solution of many problems. However, the range of any scale (except the D-scale) may be extended quite simply, because the scales are logarithmic. For instance, suppose it is desirable to extend the range of the $t$-scale to include a value of $t$ equal to 1000 days. Since the length of the segment of the $t-s c a l e$ between the points marked 10 and 100 is equal to the length of the segment of the t-scale between the points marked 100 and 1000 , the point corresponding to $t=1000$ is located by extending the $t$-scale until the above mentioned segments are equal.

A value of 484 barns is used as the corrected thermal neutron cross section for fission of $U^{235}$. It represents the effective cross section for fission if it is assumed that the thermal neutron flux has a Maxwellian distribution.

The depletion of the $\mathrm{U}^{235}$ is considered to be accomplished as a result of fission only. Also, the total atom burnup refers only to the burnup of the $\mathrm{U}^{235}$.

In using the alignment charts, an error greater than $\pm 5 \%$ is very unlikely if care is exercised in locating points on the various scales. This error is smaller than the probable error accumulating as a result of other uncertainties occurring during the irradiation of uranium. 







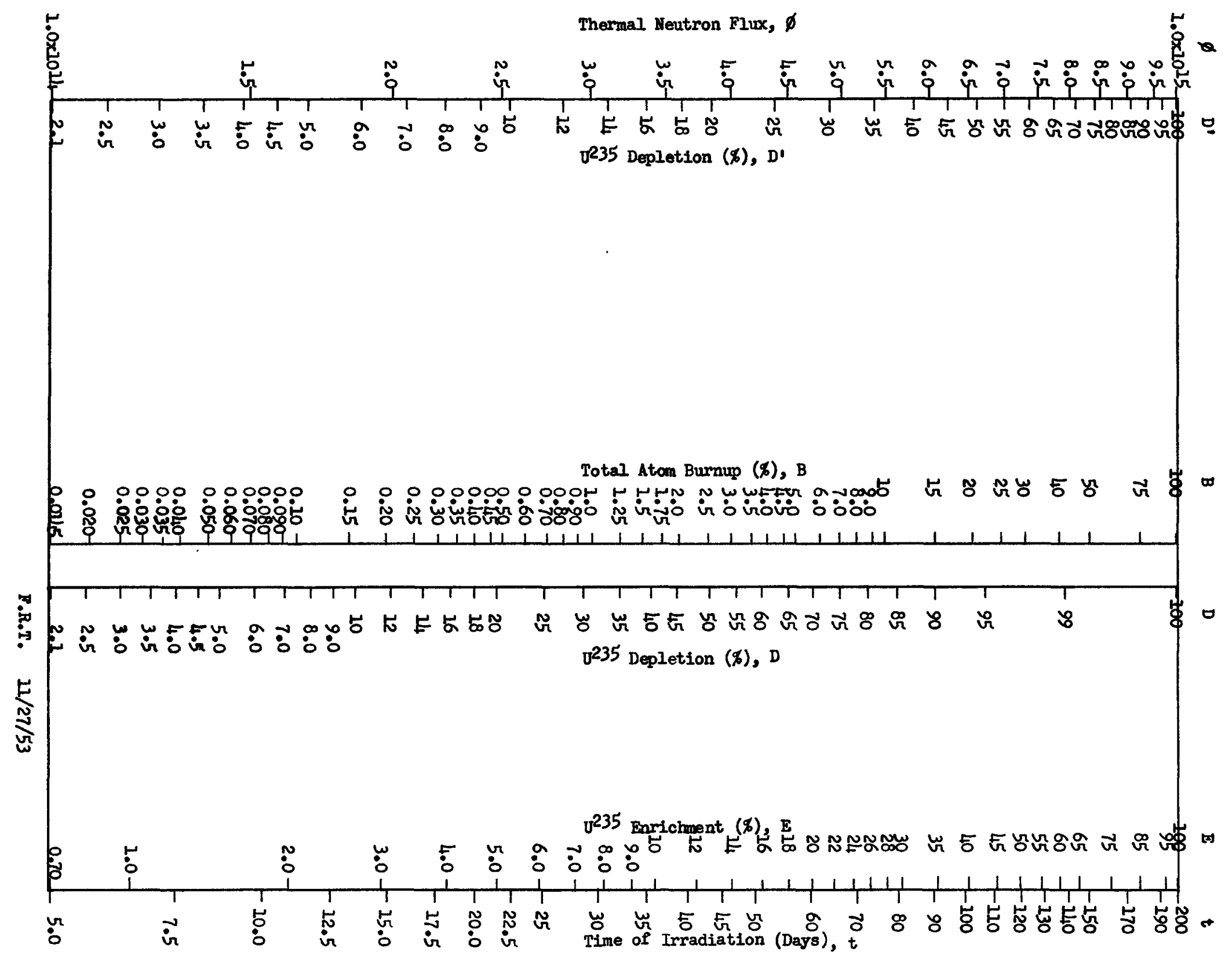






